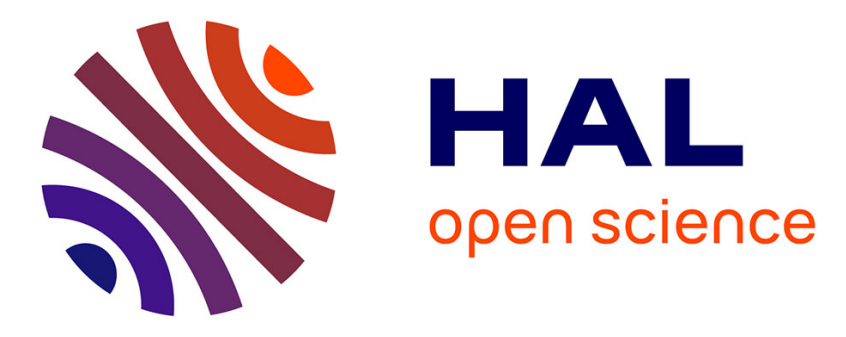

\title{
Long-term impact of full-thickness rectal prolapse treatment on fecal incontinence.
}

Timothée Wallenhorst, Guillaume Bouguen, Charlène Brochard, Diane Cunin, Véronique Desfourneaux, Alain Ropert, Jean-François Bretagne, Laurent Siproudhis

\section{To cite this version:}

Timothée Wallenhorst, Guillaume Bouguen, Charlène Brochard, Diane Cunin, Véronique Desfourneaux, et al.. Long-term impact of full-thickness rectal prolapse treatment on fecal incontinence.. Surgery, 2015, 158 (1), pp.104-111. 10.1016/j.surg.2015.03.005 . hal-01146244

HAL Id: hal-01146244 https://hal-univ-rennes1.archives-ouvertes.fr/hal-01146244

Submitted on 18 Sep 2015

HAL is a multi-disciplinary open access archive for the deposit and dissemination of scientific research documents, whether they are published or not. The documents may come from teaching and research institutions in France or abroad, or from public or private research centers.
L'archive ouverte pluridisciplinaire HAL, est destinée au dépôt et à la diffusion de documents scientifiques de niveau recherche, publiés ou non, émanant des établissements d'enseignement et de recherche français ou étrangers, des laboratoires publics ou privés. 
Title: LONG-TERM IMPACT OF FULL-THICKNESS RECTAL PROLAPSE TREATMENT ON FECAL INCONTINENCE.

Runing Head: Fecal incontinence in rectal prolapse

Timothée Wallenhorst, $\mathrm{MD}^{1}$, Guillaume Bouguen, $\mathrm{MD}^{1,2}$, Charlène Brochard, $\mathrm{MD}^{1}$, Diane Cunin, MD³, Véronique Desfourneaux, MD³, Alain Ropert, MD¹, Jean-François Bretagne, $\mathrm{MD}, \mathrm{PhD}^{1,}$, Laurent Siproudhis, MD, $\mathrm{PhD}^{1,2}$

1. Department of Hepato-Gastroenterology, University Hospital of Rennes, Pontchaillou, France

2. INSERM U991, University of Rennes 1, Rennes, France

3. Department of Hepatobiliary and Digestive Surgery, University Hospital of Rennes, Pontchaillou, France

\section{Corresponding author:}

Prof Laurent SIPROUDHIS, MD, PhD

Service des Maladies de l'Appareil Digestif

CHU Pontchaillou, 2 rue Henri le Guilloux

35033 Rennes Cedex, FRANCE

Phone: + 33299284317

Fax: + 33299284189

Email address: laurent.siproudhis@chu-rennes.fr

\section{Conflicts of Interest and Source of Funding:}

All authors have no financial disclosure to be acknowledged. This work did not receive any financial support.

Word count: text 2854; abstract 265.

Author contributions: TW, GB and LS performed study design, interpretation and analysis of data, editing of the manuscript. TW \& DC performed collection of data.

LS performed statistical analysis. VD operated the patients. AR performed physiology assessments. All authors reviewed the paper and approved the final submitted draft.

Category: Anorectal disease. 


\section{ABSTRACT}

Background: Fecal incontinence is frequently associated with rectal prolapse, but little is known about recovery after treatment of the prolapse.

Objective: We therefore aimed to investigate the long-term outcome of fecal incontinence in a cohort of patients suffering from full-thickness rectal prolapse.

Design: A database was prospectively compiled over a 7-year period (2003-2010) of 145 patients diagnosed with full-thickness rectal prolapse.

Main outcome measures: Patients were referred to a single institution and assessed by standardized questionnaires, anorectal manometry, endosonography, and evacuation proctography. Fecal incontinence was evaluated according to the Cleveland Clinic Score: continence improvement was defined by at least 50\% improvement of the Cleveland Clinic Score.

Results: Among the population studied (134 women, 11 men, median follow-up 38.9 [21.2-67.2] months), 103 (71\%) patients underwent surgery for their prolapse and 42 (29\%) did not. According to the Cleveland Clinic Score, 139 (96\%) patients suffered from fecal incontinence before treatment and 64 (46\%) patients reported improvement at the end of the follow-up. Pre-treatment history of incontinence symptoms longer than 2 years (Hazard Ratio=1.99; 95\% CI\%, 1.14-3.46; $p=0.015$ ) and ventral rectopexy (Hazard Ratio=1.86; 95\% CI\%, 1.026-3.326; $p=0.04$ ) were associated with continence improvement. Patients who underwent a surgical procedure other than ventral rectopexy had similar outcome as compared to non-operated patients. Conversely, chronic pelvic pain precluded fecal incontinence improvement (Hazard Ratio=0.32; 95\% СI\%, 0.135-0.668; $p=0.0017$ ).

Limitations: Follow-up, returned questionnaires, and the heterogeneous reasons put forth for declining surgery may introduce some methodological bias.

Conclusion: Fecal incontinence in patients suffering from rectal prolapse is improved when ventral rectopexy is performed as compared to other surgical or medical therapy.

Keywords: Rectal prolapse; fecal incontinence; surgery; rectopexy. 


\section{INTRODUCTION}

Full-thickness rectal prolapse is a circumferential eversion of the rectal wall through the anal canal leading to external prolapse, fecal urgencies, mucus discharge and tenesmus. Its incidence is about 2.5 per 100000 of the general population. ${ }^{1}$

Fecal incontinence is often the main complaint that dramatically alters quality of life, occurring in $25-78 \%$ of patients prior to surgery. ${ }^{2}$ In a large and consecutive series of patients suffering from rectal prolapse, age and previous hemorrhoid surgery were associated with fecal incontinence. ${ }^{3}$ Surgery is the most valuable way to treat overt rectal prolapse. Non-operated patients are less likely to have their fecal incontinence improve. ${ }^{4}$ Several surgical techniques for the repair of rectal prolapse have been promoted aiming to provide a durable result and to suppress mucus discharge and urgency associated with fecal incontinence. However, systematic reviews are unable to recommend one particular operative technique over another because of the data heterogeneity. ${ }^{5}$ Studies have reported a high rate of recovery of continence following each surgery. ${ }^{6-8}$ However, retrospective data and physician assessment may have underestimated patient dissatisfaction and post-operative fecal incontinence. A selfadministered questionnaire is less intimidating for the patient and is more appropriate. ${ }^{9}$ One recent laparoscopic rectopexy series observed an improvement in fecal incontinence for $68 \%$ of patients, but $58 \%$ still remained incontinent. ${ }^{10}$ Finally, the evolution of continence may be overestimated in studies offering only short-term follow-up. ${ }^{11}$

The aim of the study was to highlight the long-term outcome of fecal continence in a cohort of patients with overt rectal prolapse referred to a non-surgical tertiary physiology unit. The focus was to identify predictive factors of fecal incontinence improvement including patients with alternative non-surgical options.

\section{PATIENTS \& METHODS}

\section{Study population}

During a 7-year period (2003-2010), 206 patients complaining of full-thickness rectal prolapse were referred to a tertiary unit (University Hospital of Rennes, France) that provided anorectal physiology studies for evaluation of functional anorectal disorders. All had a full-thickness rectal prolapse at the clinical assessment. Standardized 
questionnaires, anorectal manometry, endosonography and evacuation proctography results were tracked in a prospective database. A self-administered questionnaire was mailed to the study population in May 2010. The questions specifically quantified overall satisfaction, residual prolapse symptoms, irritable bowel syndrome, continence and constipation.

The study was approved by the Hospital Ethics Committee (10th February 2010) and the Commission Nationale Informatique et Liberté (CNIL no.1412467).

\section{Functional assessment and physiology testing}

Each patient fulfilled at referral self-administered questionnaires and was assessed by physical examination, endosonography, defecating proctogram and anal manometry. Symptoms were recorded as previously described elsewhere. ${ }^{12}$ The questionnaire focused on the main anorectal complaints (e.g. external prolapse, self-reported fecal incontinence, chronic pelvic pain, dyschezia), surgical and obstetric past history. Irritable bowel syndrome was defined according to the Rome criteria. ${ }^{13}$ Validated symptom questionnaires were similar at referral and at the end of follow-up period. Fecal incontinence was evaluated by the Cleveland Clinic Incontinence Score (CCIS 020). 14 Assessment of constipation was performed using the validated KnowlesEccersley-Scott Symptom Constipation Score (KESS-CS 0-39). Constipation was defined by a score of 10 and more. ${ }^{15} \mathrm{Fecal}$ incontinence was defined by a CCIS $>0$ (patients with a CCIS $=0$ where fully continent). Mild incontinence was defined by a CCIS $>4$. Severe incontinence was defined by a CCIS $>7 .{ }^{16}$ Continence improvements at the end of followup were defined by a reduction of at least $50 \%$ of the CCIS as compared to baseline.

Quality of life was quantified using a validated scale for gastrointestinal complaint (GIQLI 0-144), urinary incontinence with the Urinary Distress Inventory (UDI) scale, the stress urinary scale (K Bo index) and the quality of life scale (Ditrovie) as previously published in fecal incontinence cohorts. ${ }^{17-19}$

Anal manometry was performed using a triple-lumen, water-perfused catheter (R3B and PIP4-4; Mui Scientific, Mississauga, Ontario, Canada) to record the mean maximal resting pressures in the upper and lower anal canal. The mean squeeze pressure in the lower anal canal was obtained during a 30 s squeeze. Rectal perception threshold was recorded using isovolumic distension with balloon air inflation. Anal endosonography (B\&K Medical $10 \mathrm{MHz}$ probe; Bruël Kjaer, Toulouse, France) was performed to assess 
the morphology of the internal and external sphincters. Sphincter lesions were recorded, and the thickness of each sphincter was expressed as the mean of three separate measures.

Defecography was performed as previously described using the barium contrast medium (Microtrast $\left(\right.$ ) through oral, vaginal and anal routes. ${ }^{20}$ The bladder was not catheterized. Rectal filling was sufficient to materialize the sigmoid loop. The ileum was filled by the oral intake of barium (Micropaque $($ ) 90 min before the radiological examination. This radiological examination helped to identify and quantify internal intussusception, high-grade prolapse, perineal descent, rectocele, enterocele or sigmoidocele and rectal emptying. internal intussusception and high-grade prolapse were defined by an intra-anal or exteriorized intussusception of the rectal wall during straining according to the radiological classification. ${ }^{21}$ Enterocele was defined as a radiological hernia of the small bowel into the recto-vaginal space, as previously described. ${ }^{22}$ Perineal descent was quantified by the maximal length that separated the upper anal canal site and the pubo-coccygeal line during defecation. ${ }^{21}$

\section{Therapeutic procedures and follow-up}

The main strategies are summarized in figure 1.

\section{Non-surgical treatment}

Non-surgical options were based on the French Guidelines for therapeutic management of fecal incontinence. ${ }^{23-24}$ The bowel management was adapted by the physician with dietary counselling (dietary book support). Stool transit modifying drugs were used according to the quality of bowel transit. A physical therapy retraining protocol was based on 20 sessions of 30 min each, all performed within a 4-month period at an initial rate of two sessions per week. These sessions were completed by daily home-based anal exercises. A total of 42 (29\%) patients were treated with medical therapy alone according to guidelines. The surgery was declined due to gastroenterologist recommendation for medical strategy in 13 patients and by the surgeon in 14 patients (reasons included low benefit/risk ratio, concomitant history of anorexia nervosa or Crohn's disease and of unstable cardiovascular disease). Delayed procedure were performed in two women who planned pregnancy. Finally, 15 patients declined the proposed operation. 


\section{Surgical technique}

Surgical laparoscopic techniques for full-thickness rectal prolapse have been previously described. The procedures included ventral and non-ventral rectopexies, the former being the most common. ${ }^{8,25}$ Two senior surgeons performed the procedures. Historically, ventral rectopexies were performed in all patients after 2005 whereas other conventional pexies (Orr-Loygue, anterior and posterior pexies) were mainly performed between 2003 and 2005 according to the recommended rectopexies at that time. Transanal approaches have been chosen in patients with very poor anaesthetic conditions.

A total of 103 (71\%) patients underwent surgery for their prolapse. Of these, 7 out of $103(6.8 \%)$ patients underwent a transanal procedure (1 Altemeier, 6 Delorme), and 96 out of 103 (93.2\%) an abdominal rectopexy (by laparoscopy for 94 out of 96 patients). Rectopexies consisted of ventral rectopexies for 63 out of 103 (61.2\%) patients, OrrLoygue rectopexies for 11 out of 103 (10.7\%) and anterior and posterior mesh insertions after mobilization of the mesorectum for 20 out of 103 (19.4\%) patients. Two out of 103 (1.9\%) patients underwent an open rectopexy associated with a sigmoidectomy to control a marked preoperative constipation.

\section{Follow-up}

The follow-up was determined by the duration between the initial referral and the date of the completion of the final self-administrated questionnaire (May 2010).

\section{Statistical analysis}

Quantitative variables were expressed as median and percentile (interquartile range [IQR], 25\% and 75\%). Categorical variables were presented as counts and percent of the cohort. Qualitative variables were expressed as positive values. The cumulative probability of fecal incontinence improvement was estimated by using the Kaplan-Meier method. To identify factors predictive of significant fecal incontinence improvement, we performed a univariate analysis by using the log-rank test. Patients without incontinence over time (CCIS=0) could not be assessed for improvement of incontinence and their data were withdrawn from the actuarial analyses. To identify independent predictors of fecal incontinence by using a multivariate analysis, all significant variables with $p$ values $<0.05$ in the log-rank test were retained in the model and integrated into a 
Cox proportional hazards regression model. The results are shown as hazard ratios (HRs) with 95\% confidence intervals [CIs].

Statistical analyses were performed using JMP® Pro 9.0.2 Software (SAS Institute Inc, Cary, NC).

\section{RESULTS}

\section{Study population}

Among the 206 patients referred for a full-thickness rectal prolapse, 26 (12.6\%) patients declined to complete the questionnaire, 8 were not able to do so, 9 patients died from unrelated diseases and 18 (8.7\%) patients were lost of follow-up. Thus, our completed study group constituted 145 (70.4\%) patients. Despite the prospective database, some items were not obtained for all patients (see table footnotes). Table 1 represents the baseline characteristics at referral of the study population that included 134 (92.4\%) women and 11 men (aged 60 [45 - 72] years). The median body mass index was 22.1 [19.8 - 25] kg/m². A total of 35 (24.1\%) patients had prior history of hemorrhoidectomy and $9(6.2 \%)$ patients underwent prior surgery for rectal prolapse. External prolapse was the main complaint in $61(42 \%)$ patients and $21(15.7 \%)$ patients suffered from chronic pelvic pain. According to CCIS, 21 patients (14.5\%) had mild fecal incontinence $(0<\mathrm{CCIS}<5), 15(10.3 \%)$ patients had moderate fecal incontinence $(4<\mathrm{CCIS}<8)$ and 91 (62.8\%) had severe fecal incontinence (CCCIS>7). Only 18 (12.4\%) patients did not suffer from fecal incontinence (CCIS=0) at the initial presentation. At defecography, perineal descent was present in 134 patients (92.2\%). Despite an external prolapse on clinical assessment, rectal prolapse was radiologically intra-rectal, intra-anal and exteriorized for 21 (15.1\%), 29 (20.9\%) and 89 (64\%) patients, respectively. Anal endosonography identified defects of the internal anal sphincter in 45 (42.5\%) patients. Results of the anorectal physiology are depicted in Table 2. A total of 103 (71\%) patients underwent surgery for their prolapse. Of these, seven out of 103 (6.8\%) patients underwent a transanal procedure (one Altemeier and six Delorme), and 96 out of 103 (93.2\%) underwent an abdominal rectopexy (by laparoscopy for 94 out of 96 patients). Rectopexies consisted of ventral rectopexies for 63 out of 103 (61.2\%) patients, OrrLoygue rectopexies for 11 out of 103 (10.7\%), and anterior and posterior mesh insertions after mobilization of the mesorectum for 20 out of 103 (19.4\%) patients. Two 
out of 103 (1.9\%) patients underwent an open rectopexy associated with a sigmoidectomy.

\section{Long-term outcomes of fecal incontinence}

After a median follow-up of 38.9 [21.2 - 67.2] months (extremes: 6-91 months), 64 (50\%) of the 127 patients with incontinence at referral reported a significant improvement in fecal incontinence (CCIS decrease of at least 50\%). Among 18 patients who did not suffer from fecal incontinence initially (CCIS=0), 12 complained of incontinence on follow-up despite a rectopexy in 11 of them. The median duration of follow-up after surgery for the operated patients was $36.3 \pm 25.6$ months and the median duration of follow-up after referral for the non-operated patients was $43.8 \pm$ 25.7 months. The cumulative probabilities of significant fecal incontinence improvement at $1,3,4,5$ years were $8.6 \%, 31.3 \%, 42 \%$, and $52 \%$ respectively (Figure 2).

Table 3 summarizes the variation of symptomatic scores during follow-up. According to the CCIS, Among the 145 patients of the population study, 6 (4\%) patients remained continent over the study period, fecal incontinence remained stable in 16 (11\%) patients and $86(59.3 \%)$ patients were improved. Worsening of fecal continence was reported in $43(29.7 \%)$ patients. The median constipation score did not change and the increasing score of Quality of Life was not clinically relevant.

Among the 145 patients of the population study, 48 complained of residual prolapse at the end of the follow-up: 40 after a non-operative approach and 8 after a surgical procedure. Their benefit on fecal incontinence was reported in 12/48 (25\%) versus $52 / 97(54 \%)$ in those without residual prolapse $(\mathrm{p}<0.001)$ despite a similar follow-up (42 [22 - 67] versus 37 [21 - 68] months; $p=0.7$ ). There was no difference of recurrence according to the type of surgery.

\section{Baseline factors associated with fecal incontinence improvement}

By univariate analyses (log-rank test), surgery for rectal prolapse ( $p=0.017)$, chronic pelvic pain $(p=0.016)$, resting perineal descent during defecography $(p=0.036)$, severe fecal incontinence $(p=0.0007)$, and ventral rectopexy $(p<0.0001)$ were significantly associated with fecal incontinence improvement (Table 4). Patients who underwent another surgical procedure (transanal procedures, Orr-Loygue ventropexy, anterior and posterior mesh) had the same results as patients who were not operated on for their rectal prolapse. The cumulative probabilities of fecal incontinence improvement in case 
of ventral rectopexy at 1, 3, 4, 5 years were respectively $18 \%, 56 \%, 69.3 \%$ and $79.3 \%$ (Figure 3). Other baseline characteristics were not associated with incontinence outcomes. By multivariate analysis, symptom duration more than two years prior to referral $(\mathrm{HR}=1.99 ; 95 \% \mathrm{CI} \%, 1.14-3.46 ; p=0.0148)$ and ventral rectopexy $(\mathrm{HR}=1.86$; 95\% CI\%, 1.026 - 3.326; $p=0.04$ ) were associated with an improvement of fecal continence. Conversely, chronic pelvic pain baseline precluded fecal continence improvement (HR=0.32; 95\% CI\%, 0.135-0.668; $p=0.0017)$.

\section{DISCUSSION}

The long-term outcome of fecal continence has been reported in this cohort of patients with full-thickness rectal prolapse referred to a non-surgical tertiary physiology unit. The focus was to identify baseline factors associated with fecal incontinence improvement associated with the treatment of rectal prolapse. This work suggests an increasing benefit with time, especially in patients whose prolapse was treated with ventral rectopexy. By contrast, patients treated with non-operative management experienced less benefit with their incontinence symptoms as well as a high likelihood of persistent prolapse.

This study was based on the retrospective analysis of a prospective database of patients suffering from full-thickness rectal prolapse. For this reason, there were several limitations. The long duration of the analysis period may introduce some methodological bias (variation in the surgical procedure, individual variation in follow-up, patients who did not returned their questionnaires). The heterogeneous reasons put forth for declining surgery represent another limitation in this study. However, it allows quantifying the complaint and it is widely used in both outpatient clinics and clinical trials. The different surgical procedures that were performed may have induced biases as they were done based on surgeon preference that was impacted by the condition of the patient (as opposed to a randomized, controlled fashion). Changes in operative choice during the study period, including the development of the ventral rectopexy, may have impacted the results (especially with those patients therefore having shorter follow- up). Additionally, there were no follow-up imaging or physiology studies available to compare to the baseline studies, thus making conclusions about reasons for the fecal incontinence improvements difficult to determine. 
The main strengths of the study are the duration of follow-up (more than three years) combined with standardized monitoring and evaluation of fecal incontinence with selfadministered questionnaire. Moreover, the inclusion of rectal prolapse patients undergoing non-operative treatment in the study cohort gives an unbiased assessment as compared to other studies in the literature focused on only surgical cohorts.

Fecal incontinence is a disabling condition that has dramatic emotional and physical impacts on quality of life. ${ }^{3}$ This issue must be taken into account when a treatment is needed in case of full-thickness rectal prolapse. 24 As previously shown, neither anatomical assessment nor anorectal physiology is of any help in selecting patients at risk of incontinence before surgery. ${ }^{9}$

After rectopexy, continence improvement rates have varied from 30 to $88 \% .{ }^{6}$ Because of the multifactorial mechanism of incontinence in full-thickness rectal prolapse, we believe that the incontinence has large inter-individual and temporal variability where surgery is one among several variables. In the present work, ventral rectopexy seems to offer a better improvement in fecal incontinence outcome than other surgical techniques. Patients with non-ventral procedure were not improved as compared to non-operated patients. We can speculate that sparing dissection avoids a posterolateral damage of the autonomic innervation. ${ }^{25}$ In another way, continence improvement may better benefit patients with moderate or low incontinence score. However, the present study demonstrates that patients having severe incontinence were those who improved better over time. Another key point of the study is the late recovery of continence after surgery. In fact, only $18 \%$ of patients improved within the first year after surgery. This is a message of patience after prolapse surgery for patients suffering from fecal incontinence. This may be related to a long recovery after pelvic nerve stretching as already experienced in post-partum incontinence. Another hypothesis may be the impact of the prolapse itself on the anal sphincter which may improve over time after repair. ${ }^{26}$

Finally, patients with pre-operative pelvic pain had less improvement of fecal incontinence as compared to patients without pre-treatment pelvic pain. This parameter has been shown to be associated to a low satisfaction rate in a previous study assessing hemorrhoidal surgery. ${ }^{12}$ The reason remains unclear but it needs to be taken into consideration before planning surgery. 


\section{Conclusion:}

When surgery is chosen to treat rectal prolapse, both patients and physicians need to be aware of the long time before recovery of pre-treatment fecal incontinence, which appears to gradually improve between one and five years after the operation. There is limited evidence from our study that ventral rectopexy should be preferred over the other surgical techniques in regards to its better outcome related to fecal incontinence. 


\section{Tables}

Table 1. Main baseline characteristics of study population at referral. IQR: interquartile range.

\begin{tabular}{|c|c|c|}
\hline Characteristics & $\begin{array}{l}\text { Number (\%) } \\
\text { or median IQR [25-75] }\end{array}$ & $\mathrm{N} \#$ \\
\hline Age, years & $60[45-72]$ & 145 \\
\hline Sex, male/female & $11(7.6) / 134(92.4)$ & 145 \\
\hline Median follow-up, months & $38.9[21.2-67.2]$ & 145 \\
\hline Follow-up $>4$ years & $59(40.7)$ & 145 \\
\hline Follow-up $>3$ years & $79(54.5)$ & 145 \\
\hline Symptom duration, months\# & $24[12-61.3]$ & 106 \\
\hline Symptom duration $>4$ years & $50(47)$ & 106 \\
\hline Symptom duration $>3$ years & $56(53)$ & 106 \\
\hline Body mass index, $\mathrm{kg} / \mathrm{m}^{2}$ & $22.1[19.8-25]$ & 108 \\
\hline \multicolumn{3}{|l|}{ Past history } \\
\hline Hemorrhoidectomy & $35(24.1)$ & 145 \\
\hline Prolapse surgery & $9(6.2)$ & 145 \\
\hline Hysterectomy & $17(12.7)$ & 134 \\
\hline Parity* & $2[1-3]$ & 133 \\
\hline Vaginal delivery* & $2[1-3]$ & 133 \\
\hline Higher baby weight* $(\mathrm{kg})$ & $3.5[3.2-3.9]$ & 106 \\
\hline \multicolumn{3}{|l|}{ Main symptoms } \\
\hline Anal procidentia & $61(42)$ & 144 \\
\hline Fecal incontinence & $36(25)$ & 144 \\
\hline Tenesmus and discharge & $21(14.6)$ & 144 \\
\hline Dyschezia & $11(7.6)$ & 144 \\
\hline Digitation\# & $48(36.6)$ & 131 \\
\hline Chronic pelvic pain\# & $21(15.7)$ & 134 \\
\hline \multicolumn{3}{|l|}{$\begin{array}{l}\text { Self-reported fecal } \\
\text { incontinence\# }\end{array}$} \\
\hline Passive & $71(51.6)$ & 138 \\
\hline Urgency & $24(17.4)$ & 138 \\
\hline Combined & $16(11.6)$ & 138 \\
\hline Urinary incontinence\# & $40(33.6)$ & 119 \\
\hline
\end{tabular}

\# Despite the filling of the prospective database, some items were missing because they were not recorded or the information was not obtained from the patient.

$*_{\text {for women }}$ 
Table 2. Anorectal assessment at referral. IQR: interquartile range.

\begin{tabular}{|c|c|c|}
\hline Variables & $\begin{array}{l}\text { Number (\%) } \\
\text { or median IQR [25-75] }\end{array}$ & $\mathrm{N} \#$ \\
\hline \multicolumn{3}{|l|}{ Defecography } \\
\hline Resting perineal descent & $84(65.6)$ & 128 \\
\hline Perineal descent during defecation effort & $118(92.2)$ & 128 \\
\hline Enterocele & $74(55.2)$ & 134 \\
\hline Grade 1 & $5(7.9)$ & \\
\hline Grade 2 & $15(23.8)$ & \\
\hline Grade 3 & $43(68.2)$ & \\
\hline \multicolumn{3}{|l|}{ Grade of prolapse } \\
\hline Intra rectal & $21(15.1)$ & 139 \\
\hline Intra anal & $29(20.9)$ & 139 \\
\hline Exteriorized & $89(64)$ & 139 \\
\hline Rectocele & $12(9.1)$ & 132 \\
\hline Rectal emptying & $72(67.1)$ & 109 \\
\hline \multicolumn{3}{|l|}{ Anal Endosonography } \\
\hline Defect of external anal sphincter & $19(17.6)$ & 108 \\
\hline Defect of internal anal sphincter & $45(42.5)$ & 106 \\
\hline \multicolumn{3}{|l|}{ Anal manometry } \\
\hline Anal canal length, $\mathrm{mm}^{*}[25-50]$ & $20[15-25]$ & 122 \\
\hline $\begin{array}{l}\text { Resting pressure at the upper part of the anal } \\
\text { canal, mmHg. * }[30-90]\end{array}$ & $19[12.8-32]$ & 126 \\
\hline $\begin{array}{l}\text { Resting pressure at the lower part of the anal } \\
\text { canal, mmHg. * }[25-80]\end{array}$ & $21.5[12-34.8]$ & 124 \\
\hline Maximum voluntary squeeze effort $*>50$ & $24[15-35]$ & 124 \\
\hline Squeeze duration, $\mathrm{sec}^{*}>30$ & $30[20-30]$ & 103 \\
\hline Rectal perception threshold, $\mathrm{ml} *[5-30]$ & $10[10-20]$ & 125 \\
\hline Volume of constant perception, $\mathrm{ml} *[60-100]$ & $60[47.5-60]$ & 126 \\
\hline Maximum tolerable volume, $\mathrm{ml} *[150-350]$ & $160[120-230]$ & 121 \\
\hline
\end{tabular}

\# Despite a standard procedure, anal manometry was missing 19, anal endosonography in 38 and defecography in 6 patients. Some data were also difficult to record in several patients (perineal descent, anal length and duration of squeeze pressure).

$*$ normal values 
Table 3. Clinical scores outcomes over the study period. CCIS: the Cleveland Clinic Incontinence Score; KESS: the Knowles-Eccersley-Scott Symptom Constipation Score; GIQLI: the Gastrointestinal Quality of Life Index; KBO: the stress urinary scale; UDI: the Urinary Distress Inventory scale; IQR: interquartile range.

\begin{tabular}{|c|c|c|c|c|c|c|}
\hline & At referral & & At follow-up & & Delta & $\mathrm{p}$ \\
\hline Symptoms & $\begin{array}{c}\text { Number (\%) } \\
\text { median IQR [25-75] }\end{array}$ & $\mathrm{N} \#$ & $\begin{array}{l}\text { Number (\%) } \\
\text { median IQR [25-75] }\end{array}$ & $\mathrm{N} \#$ & median & \\
\hline CCIS & $10[4-15.5]$ & 145 & $7[3-12]$ & 145 & $-2[-1-5]$ & 0.001 \\
\hline $\mathrm{CCIS}=0$ & $18(12.4)$ & 145 & 17 (11.7) & 145 & & 0.001 \\
\hline $0<\mathrm{CCIS}<5$ & $21(14.5)$ & 145 & $36(24.8)$ & 145 & & - \\
\hline $4<\mathrm{CCIS}<8$ & $15(10.3)$ & 145 & 23 (15.9) & 145 & & - \\
\hline $7<$ CCIS & $91(62.8)$ & 145 & $69(47.6)$ & 145 & & - \\
\hline KESS & $13.5[8-21]$ & 136 & $14[6-19]$ & 137 & $-1[-6-3]$ & 0.09 \\
\hline GIQLI & 87 [70.5 - 109] & 133 & 98 [78 - 116] & 143 & $6[-4-20]$ & 0.001 \\
\hline KBO & $5[0-14]$ & 128 & $5[1-18]$ & 133 & $0[-1-5]$ & 0.12 \\
\hline UDI & $6[2-9]$ & 115 & $5[2-9.8]$ & 136 & $0[-3-2]$ & 0.53 \\
\hline
\end{tabular}

\# Despite the filling of the prospective database, some items were missing because they were not obtained from the patient. 
Table 4. Preoperative factors associated to a significant improvement of continence at the end of the follow-up (CCIS decreased of at least 50\%). CCIS: the Cleveland Clinic Incontinence Score; KESS: the Knowles-Eccersley-Scott Symptom Constipation Score; CI of HR: confidence intervals of hazard ratio.

\begin{tabular}{|c|c|c|c|}
\hline \multirow[b]{2}{*}{ Covariates } & \multirow{2}{*}{$\begin{array}{c}\text { Univariate analysis } \\
\text { (log-rank) } \\
\text { (p value) }\end{array}$} & \multicolumn{2}{|c|}{$\begin{array}{l}\text { Multivariate analysis } \\
\text { (COX proportional hazard } \\
\text { regression model) }\end{array}$} \\
\hline & & HR [95\% IC] & ( $p$ value) \\
\hline Age, years & 0.404 & & \\
\hline Body mass index, $\mathrm{kg} / \mathrm{m}^{2}$ & 0.124 & & \\
\hline $\begin{array}{l}\text { Surgical past history } \\
\text { Hemorrhoidectomy } \\
\text { Pelvic surgery }\end{array}$ & $\begin{array}{l}0.833 \\
0.533\end{array}$ & & \\
\hline $\begin{array}{l}\text { Symptom history }>2 \text { years } \\
\text { Chronic pelvic pain } \\
\text { Defecography }\end{array}$ & $\begin{array}{l}0.048 \\
0.016\end{array}$ & $\begin{array}{l}1.99[1.14-3.46] \\
0.32[0.14-0.67]\end{array}$ & $\begin{array}{l}0.015 \\
0.001\end{array}$ \\
\hline $\begin{array}{l}\text { Grade of prolapse } \\
\text { Resting perineal descent }\end{array}$ & $\begin{array}{c}0.067 \\
0.0366\end{array}$ & $0.6[0.10-3.94]$ & 0.590 \\
\hline Anal resting pressures & 0.465 & & \\
\hline $\mathrm{CCIS}>7$ & 0.0007 & $1.99[0.15-6.47]$ & 0.845 \\
\hline KESS & 0.101 & & \\
\hline $\begin{array}{l}\text { Surgery for rectal prolapse } \\
\text { Ventral rectopexy } \\
\text { Surgeon }\end{array}$ & $\begin{array}{c}<0.0001 \\
0.812\end{array}$ & $1.86[1.026-3.326]$ & 0.040 \\
\hline
\end{tabular}


Figure 1: Flowchart.

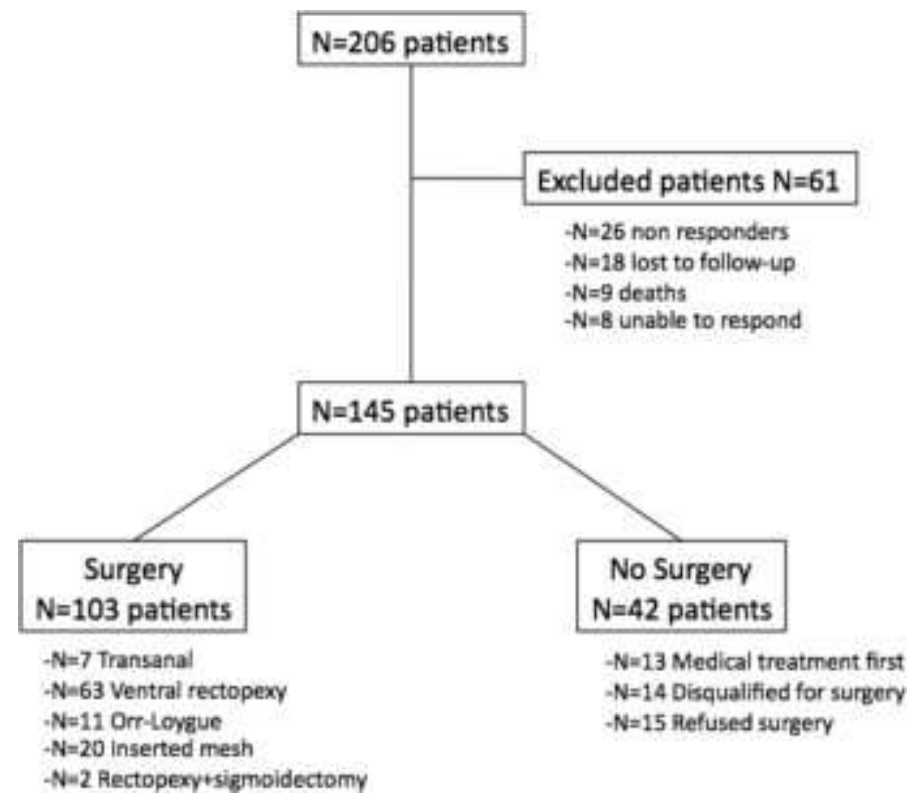

Figure 2. Cumulative probabilities of significant fecal incontinence score improvement at the end of follow-up. The cumulative probabilities of significant fecal incontinence improvement at $1,3,4,5$ years from the beginning of the management were $8.6 \%$, $31.3 \%, 42 \%$, and $52 \%$ respectively. Significant fecal incontinence improvement: CCIS decreased of at least $50 \%$ at the end of follow-up. CCIS: the Cleveland Clinic Incontinence Score.

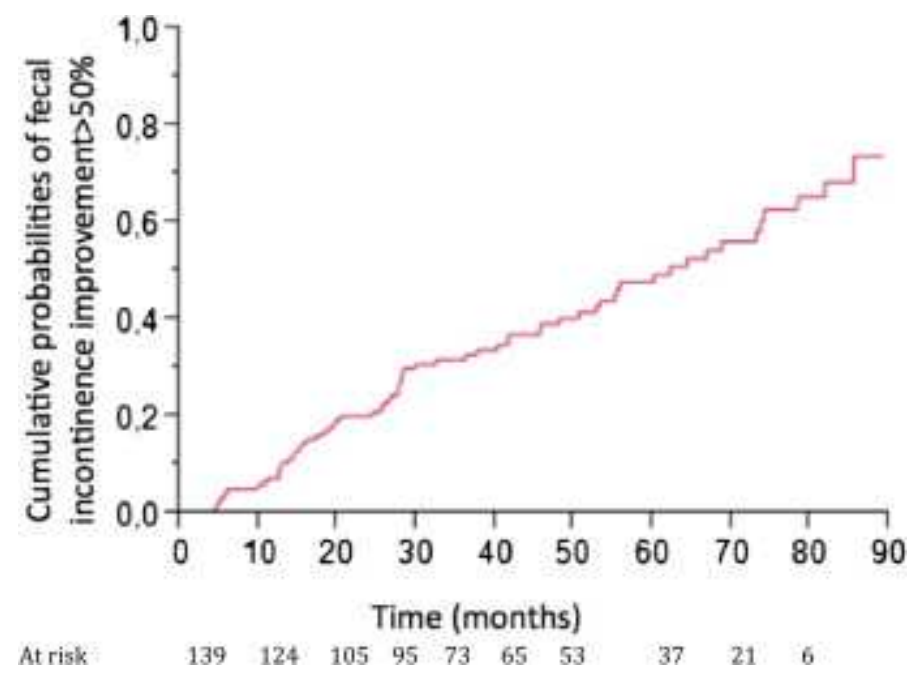

Figure 3. Cumulative probabilities of significant fecal incontinence score improvement according to three main factors (Kaplan-Meier):

(A) Surgery for full-thickness rectal prolapse. Earlier and higher incontinence improvements were observed in patients who underwent surgery as compared to those treated with non operative approach $(p=0.0017)$. 
(B) Surgical technique. Earlier and higher incontinence improvements were observed in patients who underwent ventral rectopexy as compared to those treated with other surgical methods or non operative approach $(\mathrm{p}=0.0001)$.

$(C)$ Chronic pelvic pain as a main symptom at baseline. Late and lower incontinence improvements were observed in patients who suffered from chronic pain at baseline ( $p$ $=0.016)$.

Significant fecal incontinence improvement: CCIS decreased of at least $50 \%$ at the end of follow-up. CCIS: the Cleveland Clinic Incontinence Score. 
A Surgery for rectal prolapse

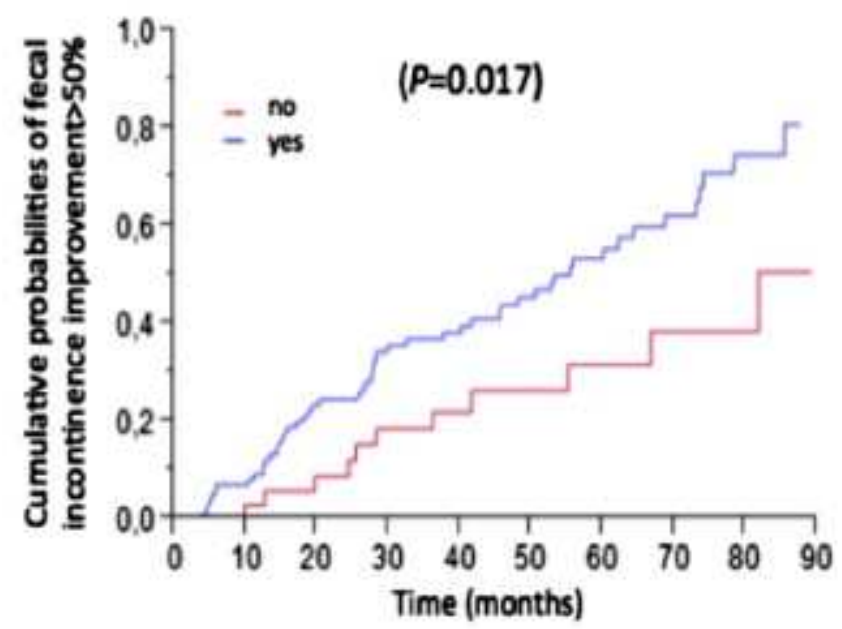

B Surgical technique

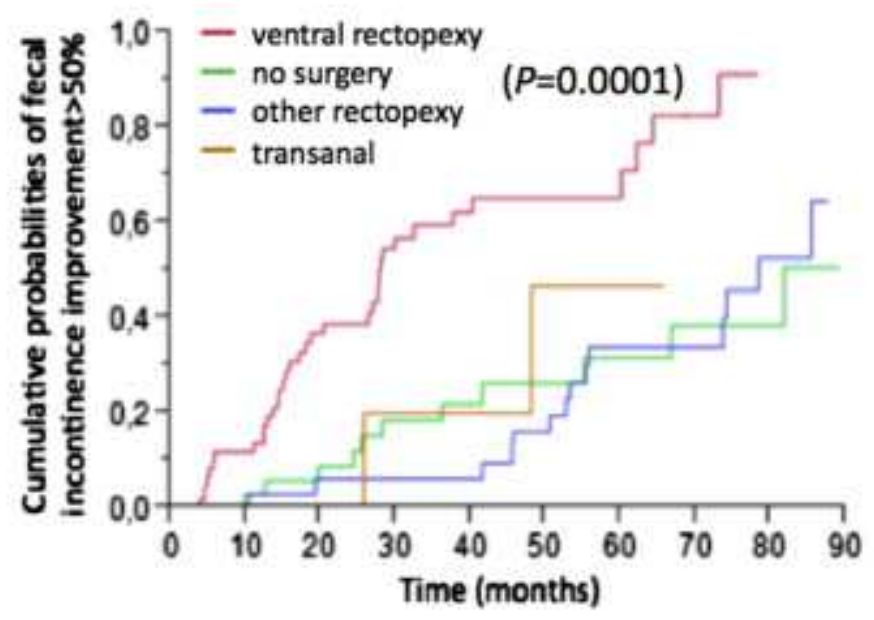

C Chronic pelvic pain

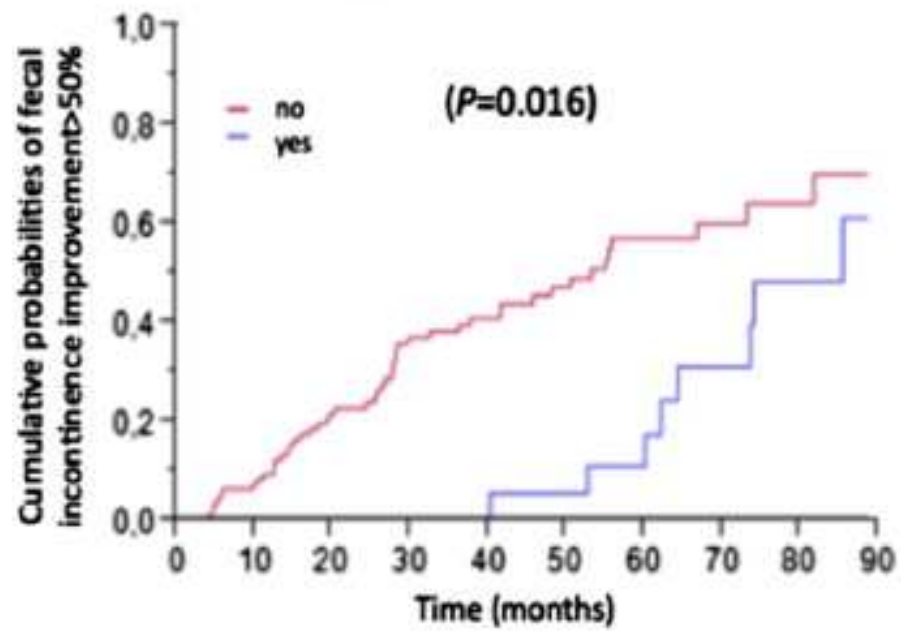

18 


\section{REFERENCES}

1. Kairaluoma MV, Kellokumpu IH. Epidemiologic aspects of complete rectal prolapse. Scand J Surg. 2005;94:207-210.

2. Marderstein EL, Delaney CP. Surgical management of rectal prolapse. Nat Clin Pract Gastroenterol Hepatol. 2007;4:552-561.

3. Siproudhis L, Eleouet M, Rouselle A, et al. Overt rectal prolapse and fecal incontinence. Dis Colon Rectum. 2008;51:1356-1360.

4. Cunin D, Siproudhis L, Desfourneaux V et al. No surgery for full-thickness rectal prolapse: what happens with continence? World J Surg. 2013;37:1297-1302.

5. Brown SR, Wadhawan H, Nelson RL. Surgery for faecal incontinence in adults. Cochrane Database Syst Rev. 2013;7:CD001757.

6. Samaranayake CB, Luo C, Plank AW, et al. Systematic review on ventral rectopexy for rectal prolapse and intussusception. Colorectal Dis. 2010;12:504-512.

7. Boons P, Collinson R, Cunningham C, Lindsey I. Laparoscopic ventral rectopexy for external rectal prolapse improves constipation and avoids de novo constipation. Colorectal Dis. 2010;12:526-532.

8. Loygue J, Nordlinger $\mathrm{N}$, Cunci $\mathrm{O}$ et al. Rectopexy to the promontory for the treatment of rectal prolapse. Report of 257 cases. Dis Colon Rectum. 1984;27:356-359.

9. Davis K, Kumar D, Stanton SL, Thakar R, Fynes M, Bland J. Symptoms and anal sphincter morphology following primary repair of third-degree tears. $\mathrm{Br} J$ Surg. 2003;90:1573-1579.

10. Cunin D, Siproudhis L, Desfourneaux V, et al. Incontinence in full-thickness rectal prolapse: low level of improvement after laparoscopic rectopexy. Colorectal Dis. 2013;15:470-476.

11. Abendstein B, Petros PE, Richardson PA, Goeschen K, Dodero D. The surgical anatomy of rectocele and anterior rectal wall intussusception. Int Urogynecol J pelvic Floor Dysfunc. 2008;19:705-710.

12. Favreau C, Siproudhis L, Eleouet M, Bouguen G, Bretagne JF. Underlying functional bowel disorder may explain patient dissatisfaction after haemorrhoidal surgery. Colorectal Dis. 2012;14:356-361.

13. Palmer BV, Lockey WJ, Palmer RB, Kulinskaya E. Improvement in irritable bowel syndrome following ano-rectal surgery. Int J Colorectal Dis. 2002;17:402-411.

14. Jorge JM, Wexner SD. Etiology and management of fecal incontinence. Dis Colon Rectum. 1993;36:77-97. 
15. Knowles CH, Eccersley AJ, Scott SM, Walker SM, Reeves B, Lunniss PJ. Linear discriminant analysis of symptoms in patients with chronic constipation: validation of a new scoring system (KESS). Dis Colon Rectum. 2000;43:1419-1426.

16. Rullier E, Zerbib F, Marrel A, Amouretti M, Lehur PA. Validation of the French version of the Fecal Incontinence Quality-of-Life (FIQL) scale. Gastroenterol Clin Biol. 2004;28:562-8

17. Eypasch E, William JI, Wood-Dauphinee S et al. Gastrointestinal Quality of Life Index: development, validation and application of a new instrument. Br J Surg. 1995;82:216222.

18. Uebersax JS, Wyman JF, Shumaker SA, McClish DK, Fantl JA. Short forms to assess life quality and symptom distress for urinary incontinence in women: the Incontinence Impact Questionnaire and the Urogenital Distress Inventory. Continence Program for Women Research Group. Neurourol Urodyn. 1995;14:131-139.

19. Amarenco G, Marquis P, Leriche A, Richard F, Zerbib F, Jacquetin B. A specific evaluation of the perturbation of life quality during voiding disorders: the Ditrovie scale. Ann Readapt Med Phys. 1997;40:21-26.

20. Siproudhis L, Ropert A, Lucas J et al. Defecatory disorders, anorectal and pelvic floor dysfunction: a polygamy? Radiologic and manometric studies in 41 patients. Int J Colorectal Dis. 1992; 7:102-107.

21. Shorvon PJ, McHugh S, Diamant NE, Somers S, Stevenson GW. Defecography in normal volunteers: results and implications. Gut. 1989;30:1737-1749.

22. Halligan S, Bartram C, Hall C, Wingate J. Enterocele revealed by simultaneous evacuation proctography and peritoneography: does "defecation block" exist? Am J Roentgenol. 1996;167:461-466.

23. Lehur PA, Leroi AM. Anal incontinence in adults. Guidelines for clinical practice. National French Gastroenterology Society. Gastroenterol Clin Biol. 2000;24:299-314.

24. Vitton $\mathrm{V}$ et al. Treatment of faecal incontinence: recommendations from the French National Society of Coloproctology. Colorectal Dis. 2014;16:159-166.

25. D’Hoore A, Pennickx F. Laparoscopic ventral recto(colpo)pexy for rectal prolapse: surgical technique and outcome of 109 patients. Surg endosc. 2006;20:1919-1923.

26. Siproudhis L, Bellissant E, Juguet F et al. Rectal adaptation to distension in patients with overt rectal prolapse. Br J Surg. 1998;85:1527-1532. 